\title{
STRATEGI BISNIS DENGAN STRATEGI SISTEM INFORMASI UNTUK PERGURUAN TINGGI
}

\author{
Hendy Wijaya; Suparto Darudiato; Tanty Octavia \\ Information Systems Department, School of Information Systems, Binus University \\ Jl. K.H. Syahdan No. 9, Palmerah, Jakarta Barat 11480 \\ hewijaya@binus.edu
}

\begin{abstract}
Information systems strategy is one important aspect in determining the direction and goals of an organization/ company. Well-directed strategic planning will bring positive influence on the existence of an organization in aligning with the vision planned in the early stages as well as in achieving the objectives. In education, strategic planning of a higher education institution plays an important role to determine the objectives to be achieved. Nowadays, competition in education is no less intense with world trade, so it requires appropriate strategic planning of any relevant factors. In this research, data collection is done by a direct survey and questionnaires at several higher educational institutions, and supported with literature study. Based on the survey, a model is created as a solution for common problems faced by the institution. Decisions through better information systems strategy will make a positive contribution to the development and quality objectives of the institution that may increase its competitiveness.
\end{abstract}

Keywords: strategic planning, education, higher education, competitiveness

\begin{abstract}
ABSTRAK
Strategi sistem informasi merupakan salah satu aspek penting dalam menentukan arah dan tujuan suatu organisasi/perusahaan ke depannya. Perencanaan strategis yang tersusun dengan baik dan terarah, akan berpengaruh positif terhadap proses ataupun kelangsungan suatu organisasi dalam menyelaraskan gerak langkah dengan visi yang telah direncanakan pada tahap awal dan dapat membantu dalam mencapai tujuan yang telah ditetapkan. Dalam dunia pendidikan, perencanaan strategi sebuah perguruan tinggi memegang peranan cukup penting guna menentukan tujuan yang ingin dicapai. Saat ini persaingan dalam dunia pendidikan tidak kalah ketatnya dengan dunia perdagangan, sehingga diperlukan perencanaan strategis yang tepat guna dari setiap faktor yang terkait. Dalam penelitian ini pengumpulan data dilakukan dengan melakukan survei secara langsung dan penyebaran kuesioner ke beberapa perguruan tinggi, serta didukung dengan studi pustaka. Berdasarkan hasil observasi, akan dibuatkan model sebagai solusi dari masalah umum yang dihadapi oleh perguruan tinggi. Melalui keputusan strategi sistem informasi yang baik pada perguruan tinggi akan memberikan kontribusi positif terhadap perkembangan serta sasaran mutu dari perguruan tinggi tersebut, sehingga dapat meningkatkan daya saing dalam dunia pendidikan saat ini.
\end{abstract}

Kata kunci: perencanaan strategis, pendidikan, perguruan tinggi, daya saing 


\section{PENDAHULUAN}

Perencanaan operasional maupun perencanaan strategis merupakan salah satu tahapan penting dalam suatu organisasi guna mengidentifikasi tujuan-tujuan serta menentukan strategi yang tepat dalam mencapai visi dan misi yang telah ditetapkan sebelumnya, hal ini dianggap sebagai aktivitas dalam konteks respon terhadap perubahan lingkungan yang dinamis. Tentunya area fungsional bertanggung jawab dalam mengembangkan rencana strategis masing-masing unit serta memberikan kontribusi dalam pencapaian rencana strategi tersebut.

Perguruan tinggi yang menggunakan sistem informasi konvensional, dan belum memiliki suatu perencanaan strategi sistem informasi, dapat dipastikan akan tertinggal dari perguruan tinggi pesaingnya yang telah memanfaatkan sistem informasi sebagai pendukung kegiatan usaha mereka.

Strategi sistem informasi dibutuhkan guna menyesuaikan gerak langkah perguruan tinggi dengan dukungan sistem informasi dan teknologi informasi yang disesuaikan dan sejalan dengan irama perkembangan perguruan tinggi tersebut agar mampu memenuhi apa yang menjadi visi, misi dan tujuan dari perguruan tinggi tersebut di masa yang akan datang. Hal yang terpenting adalah agar perguruan tinggi tersebut dapat berkembang dan bersaing di era globalisasi ini. Dengan kemudahankemudahan yang ditawarkan oleh teknologi informasi membuat teknologi informasi hampir tidak dapat lepas dari berbagai aspek kehidupan manusia pada saat ini. Sehingga penerapan ICT, membuat banyak organisasi berkembang dengan pesat (Larsen, Tonge, \& Lewis, 2007).

Pengembangan sistem informasi secara tambal sulam, tidak terencana dan tidak terkelola dengan baik akan memberikan dampak yang sangat merugikan bagi organisasi, dalam hal ini perguruan tinggikarena sistem informasi yang dikembangkan dengan tambal sulam akan menurunkan intergritas data dan proses. Sehingga harapan dari pengembangan sistem informasi yang efektif dan efisien mungkin tidak akan tercapai. Salah satu dampaknya adalah terjadi penurunan kepercayaan akan sistem informasi tersebut yang dikarenakan informasi yang dihasilkan dari pengolahan data mungkin tidak sesusai dengan yang diharapkan atau malah memberikan informasi yang tidak sesuai dengan data-data yang dimasukkan. Dengan kondisi seperti itu, maka sistem informasi akan diragukan kualitasnya dan mungkin akan membahayakan proses pengambilan keputusan bagi manajemen. Selain itu, penerapan dari sistem informasi yang tidak efektif dan efisien hanya akan membuang biaya yang besar untuk pengembangan sistem dan pemeliharaan berbagai macam perangkat lunak serta perangkat keras yang dimiliki oleh perguruan tinggi tersebut.

Berdasarkan hal-hal diatas, perlu diteliti lebih jauh beberapa hal yang mencakup: (1) bagaimana hubungan strategi sistem informasi dengan strategi bisnis? (2) aplikasi apa saja yang mampu mendukung proses bisnis dari sebuah perguruan tinggi? (3) bagaimana model sistem informasi yang cocok untuk diterapkan pada sebuah perguruan tinggi? (4) bagaimana bentuk aplikasi yang sesuai dengan proses bisnis dari sebuah perguruan tinggi?

Jelas kiranya bahwa dalam era globalisasi seperti kondisi dewasa ini, perencanaan strategi sistem informasi dan teknologi informasi yang matang dalam sebuah perguruan tinggi jelaslah sangat penting dalam meningkatkan keunggulan bersaing yang berkelanjutan. Seperti yang dikatakan Darudiato (2012), strategi harus didukung oleh kekuatan perusahaan dan dapat mengembangkan segala sarana dan pra-sarana sehingga dapat mendukung tercapainya strategi tersebut. Oleh karena itu, diharapkan melalui penelitian ini dapat memberikan hasil berupa sebuah model perencanaan strategi sistem informasi yang ideal bagi perguruan tinggi sehingga pada akhirnya mampu meningkatkan keunggulan bersaing yang berkelanjutan. 


\section{METODE}

Penelitian ini dibagi menjadi tiga tahapan yang dilakukan selama tiga tahun. Tahap pertama adalah merencanaan strategi sistem informasi pada perguruan tinggi. Tahap kedua adalah mengembangkan model dengan Metode OOAD. Tahap ketiga adalah implementasi strategi sistem informasi pada perguruan tinggi. Untuk lebih jelasnya, pada Gambar 1 di bawah ini merupakan gambaran dari kerangka pikir yang akan dijadikan acuan dalam melakukan penelitian.

Jika diperhatikan dari gambar di atas, dalam Tahap ke 1/ Tahun ke 1, terdapat aktifitas merencanakan strategi sistem informasi. Detail dari aktifitas tersebut dapat dilihat pada Gambar 2 di bawah ini.

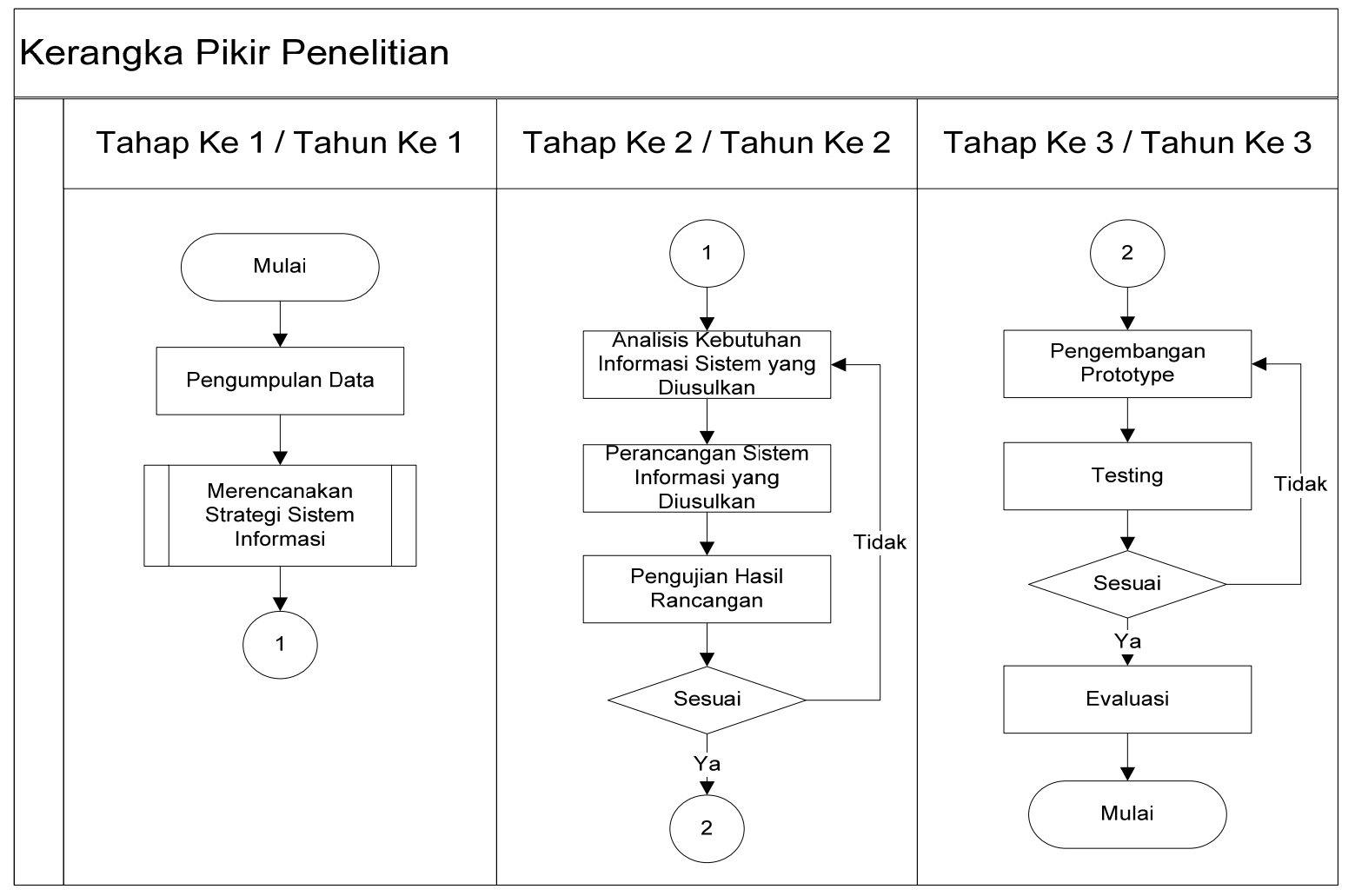

Gambar 1 Kerangka pikir penelitian 


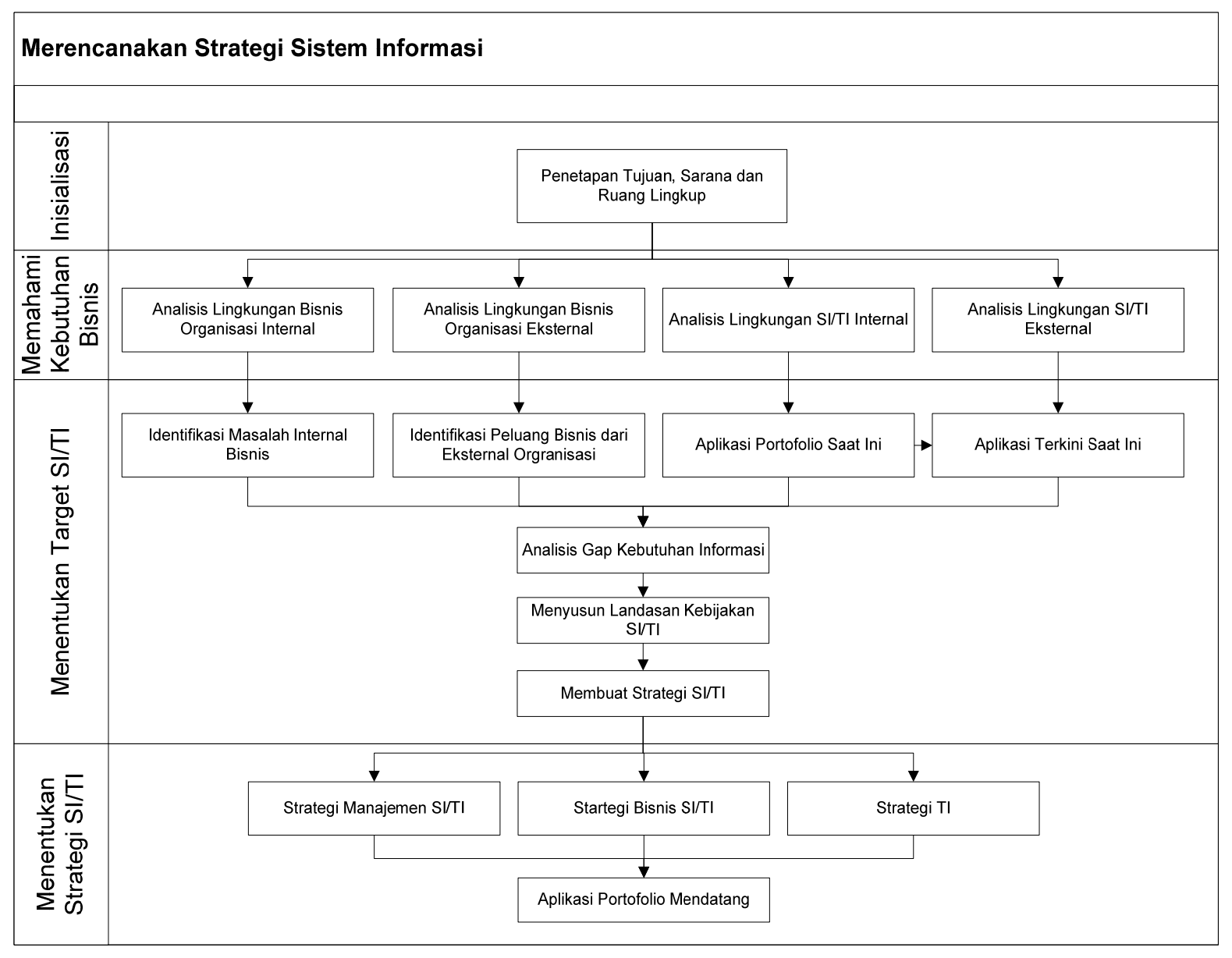

Gambar 2 Kerangka kerja perencanaan strategi sistem informasi

\section{HASIL DAN PEMBAHASAN}

Penelitian ini dimulai dengan pengumpulan data berupa visi, misi, rencana jangka panjang, inisiatif strategis, serta data terkait kondisi dan tata kelola IT. Kemudian tahap selanjutnya dilakukan langkah-langkah evaluasi tata kelola IT-nya sendiri, pada tahap ini dilakukan penentuan visi dan misi, nilai-nilai serta tujuan divisi IT. Hal ini ditentukan berdasarkan informasi yang telah dikumpulkan sebelumnya dan wawancara dengan Head of IT dari beberapa lembaga perguruan tinggi di Indonesia, mengenai tujuan yang ingin dicapai ke depannya.

Tahap selanjutnya dilakukan pengevaluasian kembali kontribusi IT terhadap sasaran strategis perusahaan yang akan menjadi dasar dalam mengembangkan sasaran strategis selanjutnya. Kemudian dilakukan identifikasi pengguna internal dan eksternal IT, serta tugas pokok dari IT, sehingga diperoleh gambaran mengenai harapan dari masing-masing kelompok stakeholder terhadap penggunaan IT.

Kemudian untuk mengidentifikasi sasaran strategis sebelumnya dilakukan analisis terhadap lingkungan internal dan eksternal dengan menggunakan kuisioner yang diklasifikasikan ke dalam kategori empat perspektif IT yang diisi oleh Head of IT yang kemudian diproses dalam mapping formula strategis. Dari formulasi strategis ini akan memperkuat penentuan pada strategi utama IT. 
Langkah selanjutnya adalah menentukan sasaran strategis yang ditentukan berdasarkan strategi dan tujuan.

Setelah itu, ditentukan ukuran-ukuran KPI yang digunakan sebagai pengukur kinerja yang terbagi menjadi dua macam ukuran. yaitu Lag Performance dan Lead Performance Indicator yang menjadi dasar dalam penentuan target dari divisi IT, di mana ditentukan berdasarkan sasaran strategis dan strategi utama IT.

Tahap selanjutnya adalah mengidentifikasi hubungan sebab akibat antar perspektif yang digambarkan pada mapping strategi dan diidentifikasi dalam Critical Success Factor guna pencapaian tujuan. Setelah dilakukan penentuan sasaran strategis masing-masing perspektif kemudian dilakukan pembobotan masing-masing perspektif dan mendetail pada masing-masing indikator. Hasil dari tahap ini adalah bobot kepentingan secara spesifik.

Setelah diketahui bobot kepentingan masing-masing indikator, maka dilakukan penilaian terhadap kinerja operasional dengan melihat realisasi dan membandingkan dengan target. Hasil dari tahap ini adalah diperoleh total skor yang menunjukkan kondisi dari kinerja divisi IT. Hasil yang diperoleh adalah kinerja IT masuk ke dalam kriteria ideal, di mana divisi IT berperan penuh dalam pencapaian strategi bisnis.

Pada tahap akhir, dilakukan penentuan berapa lama waktu/frekuensi dalam melakukan pengukuran kinerja selanjutnya dan penanggung jawab terhadap pengukuran tersebut, serta pada akhirnya adalah memberikan rekomendasi berupa inisiatif strategi sebagai respon untuk memberikan tindakan terhadap realisasi/pencapaian skor yang telah diperoleh. Inisiatif strategis ini dibagi menjadi dua bagian, yaitu langkah jangka pendek (kurun waktu 1-3 tahun) dan jangka menengah dan panjang (3-5 tahun).

\section{Identifikasi Sasaran Strategis}

Proses ini dilakukan guna melakukan penentuan sasaran, identifikasi terhadap tolak ukur beserta target yang ingin dicapai.

Sasaran strategis diidentifikasikan guna menunjang tujuan strategis, yang merupakan panduan umum dalam mengoperasionalkan tujuan mengenai kondisi ke depannya yang ingin dicapai sesuai dengan tujuan dan strategi, yaitu Corporate Contribution, User Orientation, Operational Excellence, dan Future Orientation.

Berdasarkan analisis yang telah dilakukan, diidentifikasikan sejumlah sasaran yang ingin dicapai dari divisi IT perguruan tinggi, di Jakarta, yaitu: (1) perspektif corporate contribution, yaitu bagaimana cara mengoptimalisasi pemanfaatan anggaran IT serta penghematan biaya operasional; (2) perspektif user orientation, yaitu dengan terpenuhinya kebutuhan dari para pengguna, peningkatan pengetahuan IT dari pengguna sistem, dan tercapainya hubungan kerja industry; (3) dari sisi operational excellence, yaitu dengan menjamin manajemen terhadap keamanan IT, serta meningkatkan ketersediaan penggunaan dan pengembangan aplikasi, ditambah dengan meningkatkan efektifitas dan efisiensi infrastruktur IT guna meningkatkan kualitas dari layanan; (4) future orientation, yaitu dengan mengoptimalisasi penggunaan dan pengembangan knowledge management \& organizational capital dalam lembaga, serta memaksimalkan sistem pengelolaan kinerja karyawan (KPI) dalam rangka meningkatkan kompetensi staff dan peningkatan motivasi kerja.

\section{Strategi Map}

Pada tahapan ini dilakukan proses identifikasi hubungan sebab akibat (cause and effect linkage) yang menggambarkan hubungan langsung antar perspektif. Pada mapping strategi ini 
digambarkan sasaran strategis yang diturunkan dari strategi perusahaan. Terdapat beberapa pertimbangan dalam menyusun mapping strategi, yaitu: (1) apakah mapping strategi pada IT Balanced Scorecard telah mendukung pencapaian sasaran strategi pada level perusahaan? (2) apakah sudah merefleksikan visi dan misi serta tujuan dari divisi IT yang telah disusun? (3) apakah peta strategi sudah mempertimbangkan ekspektasi dari pengguna? (4) apakah semua outcome (perspektif kontribusi dan pengguna) sudah memiliki operational excellence dan future orientation yang menunjang pencapaian outcome tersebut?

Berikut merupakan gambar mapping strategis yang disusun (Gambar 3). Tanda bintang pada gambar sasaran strategis menggambarkan turunan dari sasaran strategis perusahaan, di mana divisi IT memberikan kontribusi langsung terhadap sasaran tersebut. Peta strategi menunjukkan hubungan antara masing-masing tujuan perspektif pada IT Balance Scorecard. Tujuan pada perspektif future orientation mempengaruhi pencapaian tujuan user orientation dan corporate contribution.

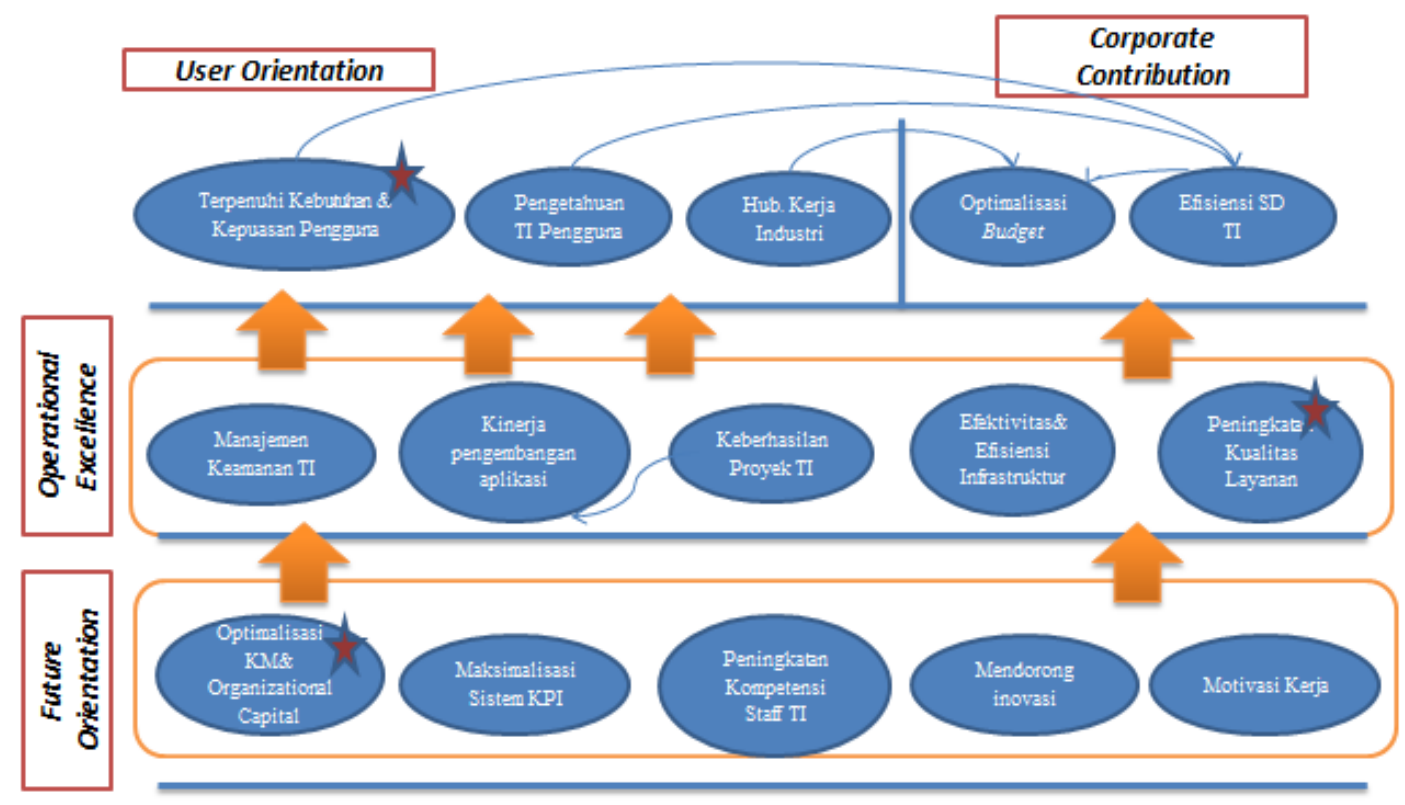

Gambar 3 Peta strategi keterkaitan antar perspektif

\section{PENUTUP}

Berdasarkan hasil dari penelitian dan analisis yang telah dilakukan pada divisi IT lembaga perguruan tinggi di Jakarta, dapat ditarik beberapa simpulan dalam evaluasi hubungan strategi bisnis terhadap strategi.

Pertama, beberapa strategi utama IT dalam mendukung pencapaian strategi bisnis lembaga, di antaranya: (1) perspektif kontribusi perusahaan: berperan sebagai contributor dalam pencapaian strategi bisnis melalui manajemen dan teknologi yang efektif; (2) perspektif pengguna: menjadi penyedia diferensiasi layanan dan produk IT; (3) perspektif operasional excellence: meningkatkan kualitas layanan IT dengan waktu dan biaya yang telah ditentukan; (4) perspektif orientasi masa depan: meningkatkan kemampuan internal dan menciptakan inovasi guna kesiapan pada perubahan dan peluang masa depan. 
Kedua, sejumlah sasaran strategis dalam pencapaian tujuan oleh divisi IT, yaitu: (1) optimalisasi pemanfaatan anggaran IT, beserta tingkat kesesuaian proyek; (2) terpenuhinya kebutuhan pengguna dalam pengetahuan dan tercapainya hubungan kerja industry; (3) terjaminnya manajemen keamanan IT, meningkatkan ketersediaan penggunaan dan pengembangan aplikasi, meningkatkan efektivitas dan efisiensi infrastruktur IT, keberhasilan proyek IT, dan meningkatkan kualitas layanan; (4) optimalisasi penggunaan dan pengembangan knowledge management \& organizational capital, memaksimalkan sistem pengelolaan kinerja karyawan (KPI), meningkatkan kompetensi staff IT, mendorong penciptaan inovasi, serta meningkatkan motivasi kerja.

Ketiga, dalam upaya meningkatkan kontribusi dari divisi IT, direkomendasikan langkahlangkah jangka pendek dan jangka panjang (Tabel 1) yang didasarkan pada hasil pengukuran efektivitas.

Table 1 Langkah-langkah untuk Meningkatkan Kontribusi dari Divisi IT

\begin{tabular}{|c|}
\hline Jangka Pendek \\
\hline $\begin{array}{ll}\text { - } & \text { Peningkatan Kualitas Layanan \& Best Practice } \\
\text { - } & \text { Peningkatan Kualitas Sumber Daya Manusia (SDM) } \\
\text { - } & \text { Dukungan dokumentasi seluruh aplikasi } \\
\text { - } & \text { Program pendidikan bagi pengguna } \\
\text { - } & \text { Pemeliharaan rutin peralatan networking } \\
\text { - } & \text { Reseaining dan Development } \\
\text { - } & \text { Reward Sistem Development } \\
\text { - } & \text { Pemanfaatan teknologi social networking dan forum }\end{array}$ \\
\hline Jangka Menengah-Panjang \\
\hline $\begin{array}{ll}\text { - } & \text { Cloud Computing } \\
\text { - } & \text { NComputing } \\
\text { - } & \text { Kerja sama dalam riset dengan perusahaan eksternal } \\
\text { - } & \text { Penyusunan blueprint keseluruhan sistem } \\
\text { - } & \text { Selective Outsourcing } \\
\text { - } & \text { Penyesuaian platform antar aplikasi } \\
\text { - } & \text { Sertifikasi ISO } 17799: 27002\end{array}$ \\
\hline
\end{tabular}

Agar hasil penelitian tahap 1 ini lebih berarti bagi perguruan tinggi, berikut ini saran-saran yang dapat dipertimbangkan untuk kemajuan dan daya saing dari perguruan tinggi: (1) perlu mempelajari arah bisnis dan perkembangan teknologi global; (2) membuat model sistem informasi yang lebih jelas; (3) menyusun cetak biru (blue print) secara menyeluruh terhadap hasil kajian ini; (3) mengembangkan aplikasi dari masing-masing cetak biru tersebut.

\section{DAFTAR PUSTAKA}

Darudiato, S. (2012). Business Performance Management; Sebuah Model Implementasi. Seminar Teknik Infromatika 2012, 258 - 265. Yogyakarta: Universitas Ahmad Dahlan.

Larsen, P., Tonge, R., \& Lewis, A. (2007). Strategic planning and design in the service sector. Management Decision , 45 (2), 180 - 195. 